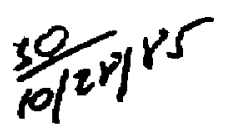

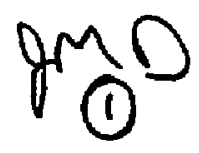

$I=23626$

(12)

$D R=1375.7$

UCID-20520

\title{
Cross Sections for X-Ray Photoelectron-Induced Desorption of Hydrogen Ions from Metal Surfaces
}

\author{
J. H. Kinney \\ W. J. Siekhaus
}

UCID- -20520

R. A. Anderson

September 20, 1985

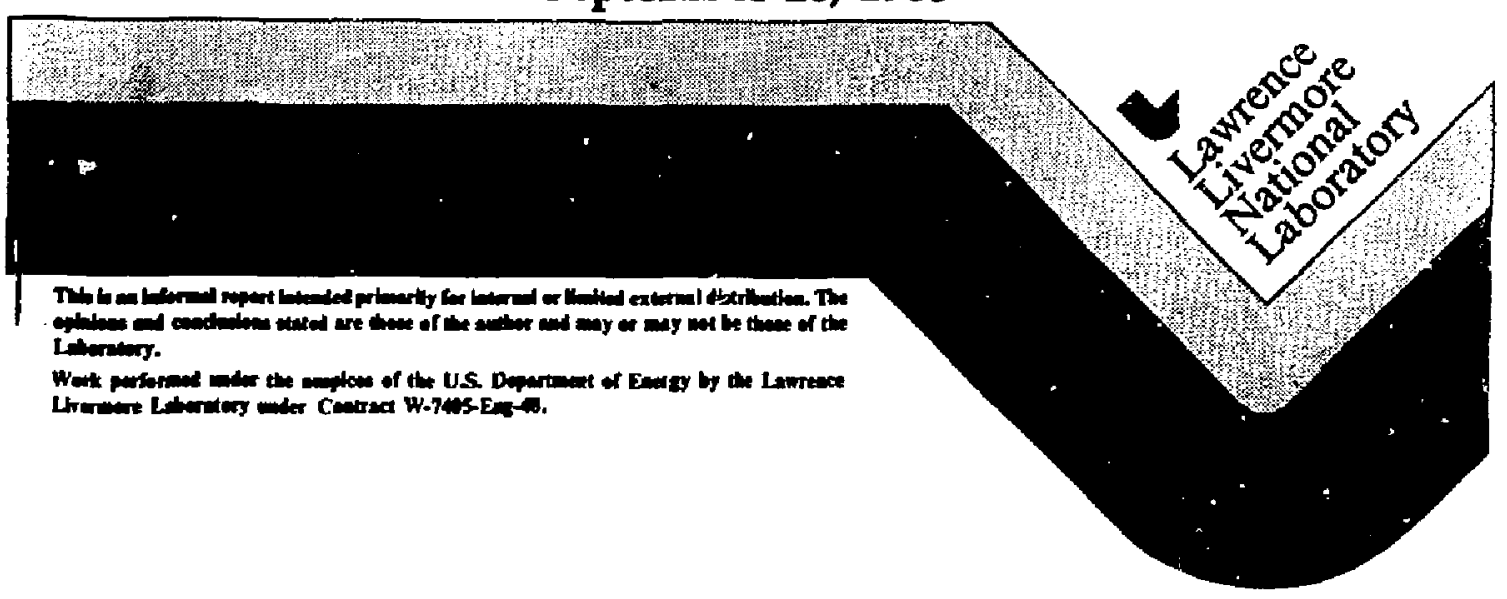

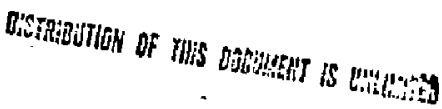


CROSS SECTIOHS FOR X-RAY PHIOTOELECTRON-INDUCED

DESORPTION OF HYDROGEN IONS FRON METAL SURFACES

\section{ABSTRACT}

We have measured the cross sections for $x$-ray photoelectron-induced desorption of hudrogen ions fron beryllium, carbon, aluninum, tantalum, and gold surfaces. This report describes the results of the cross-section measurenents, and discusses a time-of-flight technique that allows the determination of jonic-desorption cross sections as small as $10^{-25} \mathrm{~cm}^{2}$ per photoelectron.

\section{INTRDDUCIION}

The measurement of the photoelectron-induced desorption cross sections for both ions and neutrals is of practical importance in a large number of emerging technologies. For example, the vacuum designs for synclirotrons and for fusion energy machines depend criticully on the gas loads produced from photoelectron desorption. A1so, the interpretation of many weapon experiments requires at least a rough estimate of $x$-ray-induced particle emission.

With the exception of an earlier study by Brumbach and Kaminsky, 1 few measurements of $x$-ray photoelectron desorption have been made. In Brumbach's work, only the desorption of co molecules was considered. He have chosen to measure the $x$-ray photoelectron desorption cross sections of $H^{+}$off of metal surfaces because (1) few accurate measurements have been reported, (2) $\mathrm{H}^{+}$is one of the larger single species of desorbed ion, and (3) $\mathrm{H}^{+}$is one of the more difficult ions to detect using standard mass spectroscopic techniques.

This report is divided into four sections. In Section 2 we describe the $x$-ray source used, and also give details of the time-of-flight detector. In Section 3 the measured desorption cross sections from beryllium, carbon, aluminum, tantalum, and gold surfaces are given. In Section 4 we discuss the measured cross sections in terns of current models of electron-impact desorption and compare the results with cross sections obtained by other workers using energy electrons. 


\section{EXPERIMENTAL APPARATUS}

THE X-RAY SOURCE

Time-of-flight spectroscopy requires that the production of ions occurs over a time that is short with respect to the separation in time of the ion nasses that are to be identified. Furthemore, since ion desorption cross sections are very sma11, it is desirable that the current that produces the iors be large in order to obtain detectable signals.

A Field Emission Corporation Febetron, which meets both of these requirements, was a natural choice as an $x$-ray source for these experiments. The Febetron enits a lighl-current ( $4000 \mathrm{~A}$ ) narrow-pulse (5 ns) burst of electrons with energies spread between 100 and $600 \mathrm{keV}$. Figure 1 shows the measured electron energy spectrum produced by the Febetron used in this study.?

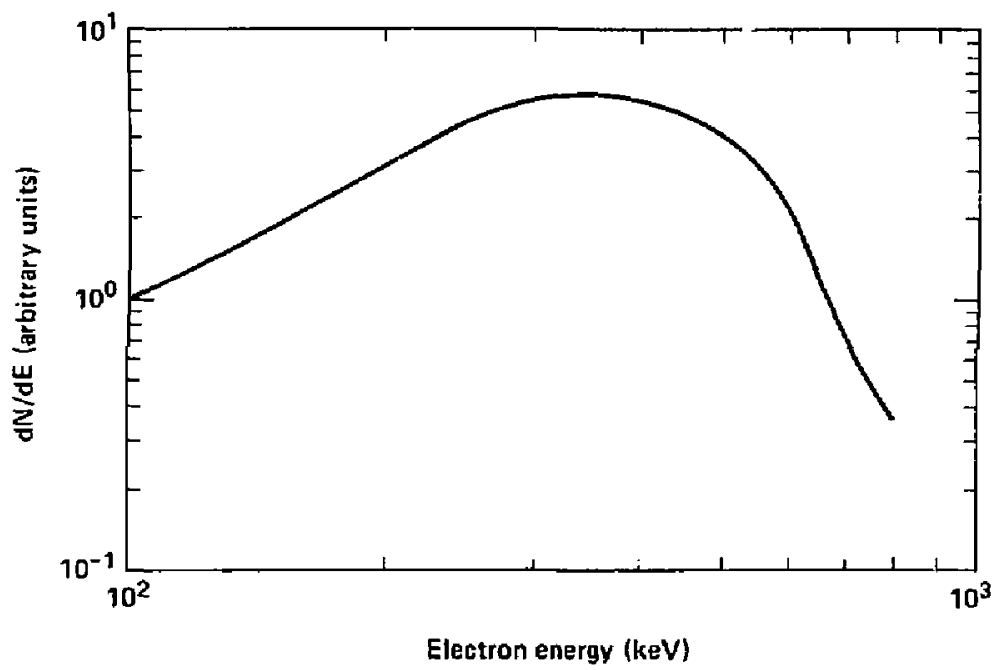

Fig. 1. The distribution in energy of electrons emitted fron the Febetron. The appearance of electrons with energies greater than $600 \mathrm{keV}$ may not be real; rather, the signal may be due to inadequate shielcing of the pin diode detectors. 


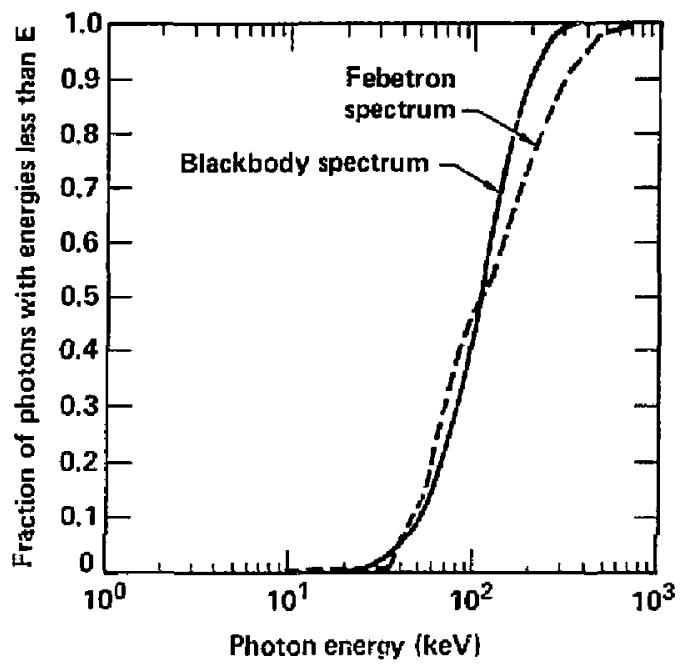

Fig. 2. The calculated integral of the $x$-ray spectrum generated by the Febetron. For comparison, a calculated integral 30-keV blackbody $x$-ray spectrum is shown. The blackbody spectrun has passed through a 0.005-in. tantalum target.

In this experiment, the field-emitted electrons from the Febetron are focussed onto a 0.005-in.-thick tantalum disk. This produces an intense, thick-target bremsstrah] ung spectrum, which has been calculated using Monte Carlo techniques. ${ }^{3}$ The result of the calculation of the $x$-ray spectrum is shown in Fig. 2. For comparison, we have al so calculated the $x$-ray spectrum produced by a 30-keV blackbody radiator. ${ }^{4}$ The suectra in Fig. 2 are integral spectra that have been normalized to 1 .

THE TIME-OF-FLIGHT ASSEMBLY

The time-of-flight assembly is shown in Fig. 3. inis assembly consists of three components: an extraction grid, a focussing cylinder lens, and a saddle field lens. Also shown in this figure are the electron drift tube emerging from the Febetron, the hard tantalum aperture used for collimation of the incident electron beam, the tantalum $x$-ray production plate, and the microchannel plate detector. 


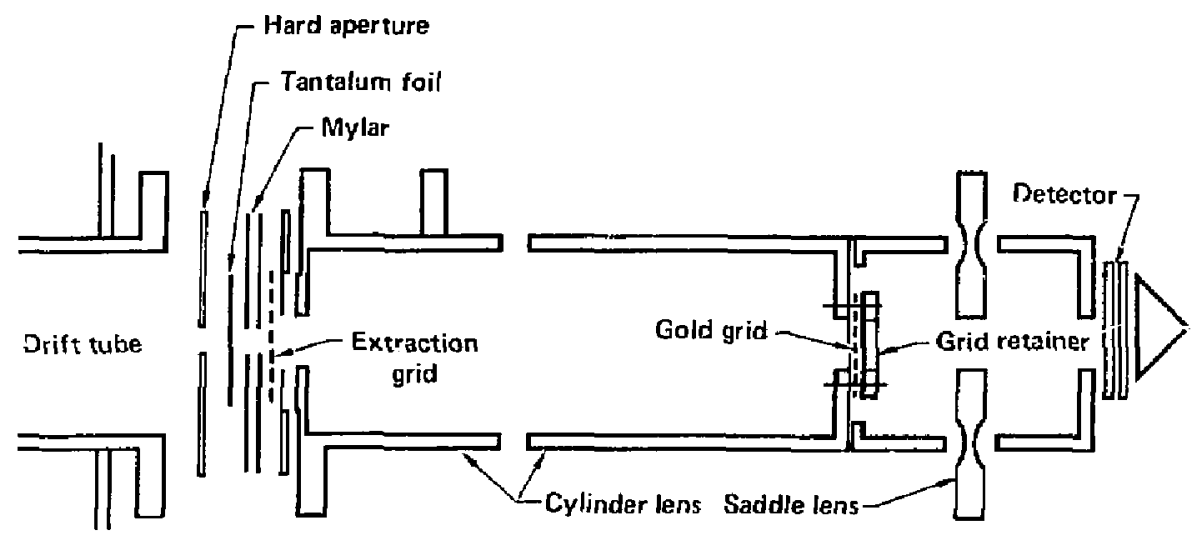

Fig. 3. The time-of-flight assembly used in this experiment.

The extraction grid is biased at $-400 \checkmark$ during operation. 1is purpose is to extract and accelerate positive ions from the target surface. It al so reduces the angular divergence of the desorbed jons. The cylindrical lens is used to focus the jons coward the detector. The front end of the lens is biased the same as the extraction grid $(-400 \mathrm{~V})$. The second stage is biased at $-2000 \mathrm{~V}$. The saddle lens is at ground potential. Its purpose is to remove all ions that are not desorbed from the surface.

A simple calculation shows why the renoval of all ions not originating at the surface was necessary for this study. First, the concentration of gas molecules per cubic centimeter at pressure $P$ is approximately

$$
c=3.6 \times 10^{16} \mathrm{P}
$$

winere $P$ is in torr. The operating pressure during this series of experinents was $3 \times 10^{-6}$ torr, indicating a volume concentration of $210^{11}$ atoms $/ \mathrm{cm}^{3}$. The surface concentration of hydrogen atoms was of the order $10^{15} / \mathrm{cm}^{2}$. Since the ionization volume for the photoelectron bean produced by the configuration of this detector is of the crder of $10 \mathrm{~cm}^{3}$, the surface desorption cross sections cannot be less than $10^{-3}$ times the volume gas ionization cross sections in order to be uniquely resolved above background. 
Because the volume ionization cross section is of the order of $10^{-19} \mathrm{~cm}^{2}$, a time-of-flight detector that does not discriminate between volume and surface jons will not resolve desorption cross sections smaller than $10^{-22} \mathrm{~cm}^{2}$ at the pressures realized in this experiment.

In order to measure cross sections smaller than $10^{-22} \mathrm{~cm}^{2}$, steps had to be taken to reduce the ionization volume. This was the purpose of the extraction grid and saddle lens. Figure 4 shows the potential energy along the z-axis of the time-of-flight tube from the target to the detector. It is apparent from energy considerations that any particle that is not ionized between the target and the extraction grid cannot sumount the saddle point. This effectively reduces the ionization volume by three orders of magnitude, which gives a detectable cross-section limit of $10^{-24} \mathrm{~cm}^{2}$. Furthemore, the volume background signal is easy to separate from the surface signal because the linear potential gradient between the extraction grid and the target spreads the volume background signal out in time. Under present

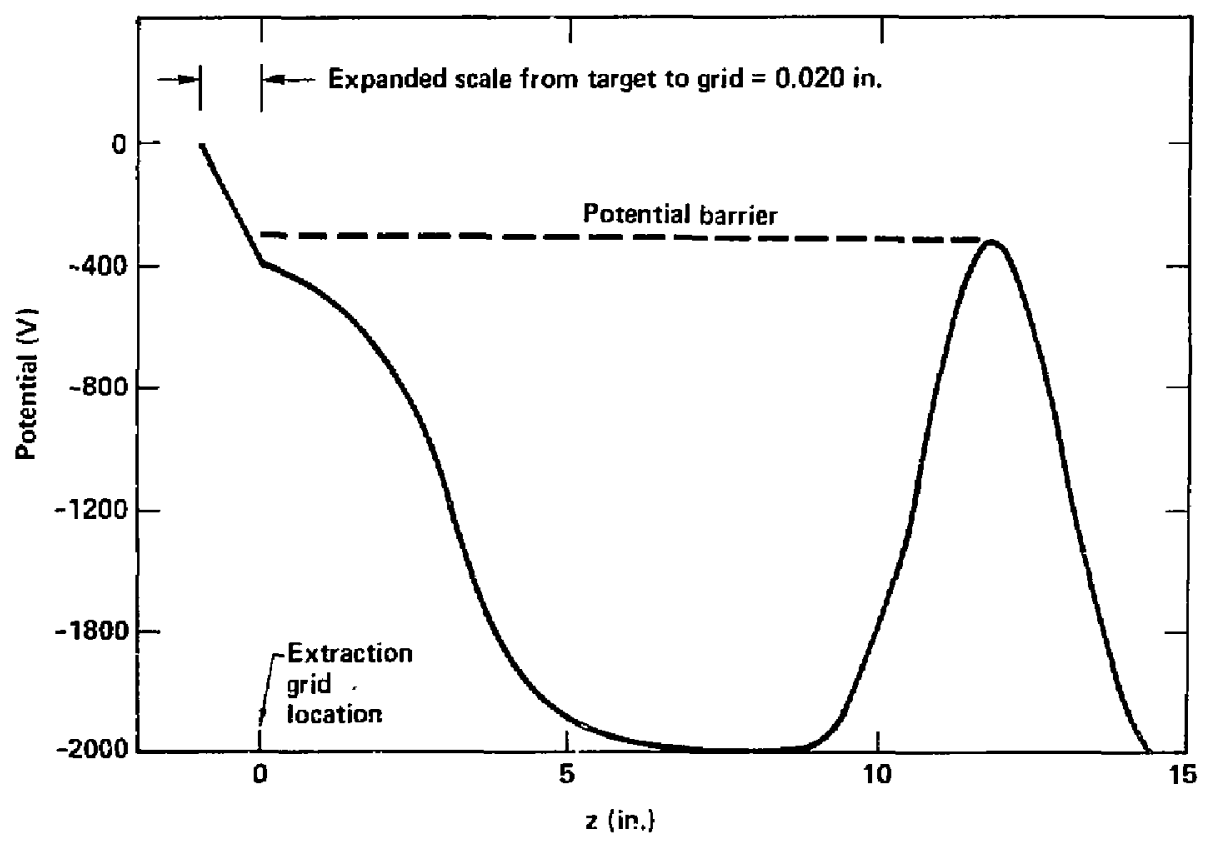

Fig. 4. Potential along the center axis $(r=0)$ of the time-of-flight tube. 
operating conditions it is possible to measure cross sections as low as $10^{-25} \mathrm{~cm}^{2}$. With an improved vacuum, we expect to be 7 imited only by the gain of the detector $\left(<10^{-26} \mathrm{~cm}^{2}\right)$.

Figure 5 shows the calculated potential contours for this time-of-flight assembly. Some sample proton trajectories, shown in Fig. $5 b$, demonstrate that only ions generated in the vicinity of the surface can reach the detector and that all other ions are turned back at the saddle point.

THE CIETECTOR

The detector consists of two microchannel plates mounted in a cherronpair configuration ${ }^{5}$ coupled to an impedance matched 50 metal anode. The gain of the detector, which was determined using a ${ }^{22} \mathrm{Na}$ source in a singleparticle count mode, is $1.2 \times 10^{7}$ when a differential plate voltage of $1000 \vee$ per plate is applied.

Ilicrochannel plate detectors have advantages over other types of detectors in this particular experimental configuration. Chief among these advantages is the ability to turn the plates on very rapidly. If the plates are left on during the initial $x$-ray:pulse, the high flux of photoelectrons hitting the detector quickly saturates the plates and makes then inoperative. Therefore, the channel plates are left off for the first 400 ns after the Febetron discharges, giving the electrons a chance to disappear. The plates are turned on just prior to the proton arrival. Because of the two grids between the time-of-flight tube and the detector, the plates can be turned on without affecting the trajectories of the ions.

Approximately $10^{3}$ protons arrive at the face of the first channel plate from a typical $x$-ray burst. The time spread is of the order of $10^{-8} \mathrm{~s}$, corresponding to a count rate of $10^{11}$ counts/s. Since this count rate is much too fast to measure in a single-particle mode, the voltage spike at the anode is integrated to give the measured charge, $Q_{m}$ :

$$
Q_{m}=\frac{1}{50} \int_{t} V(t) d t \text {. }
$$

The number of protons desorbed from the surface, $Q^{*}$, is

$$
q^{*}=\frac{Q_{m}}{G \in T_{1} T_{2}},
$$



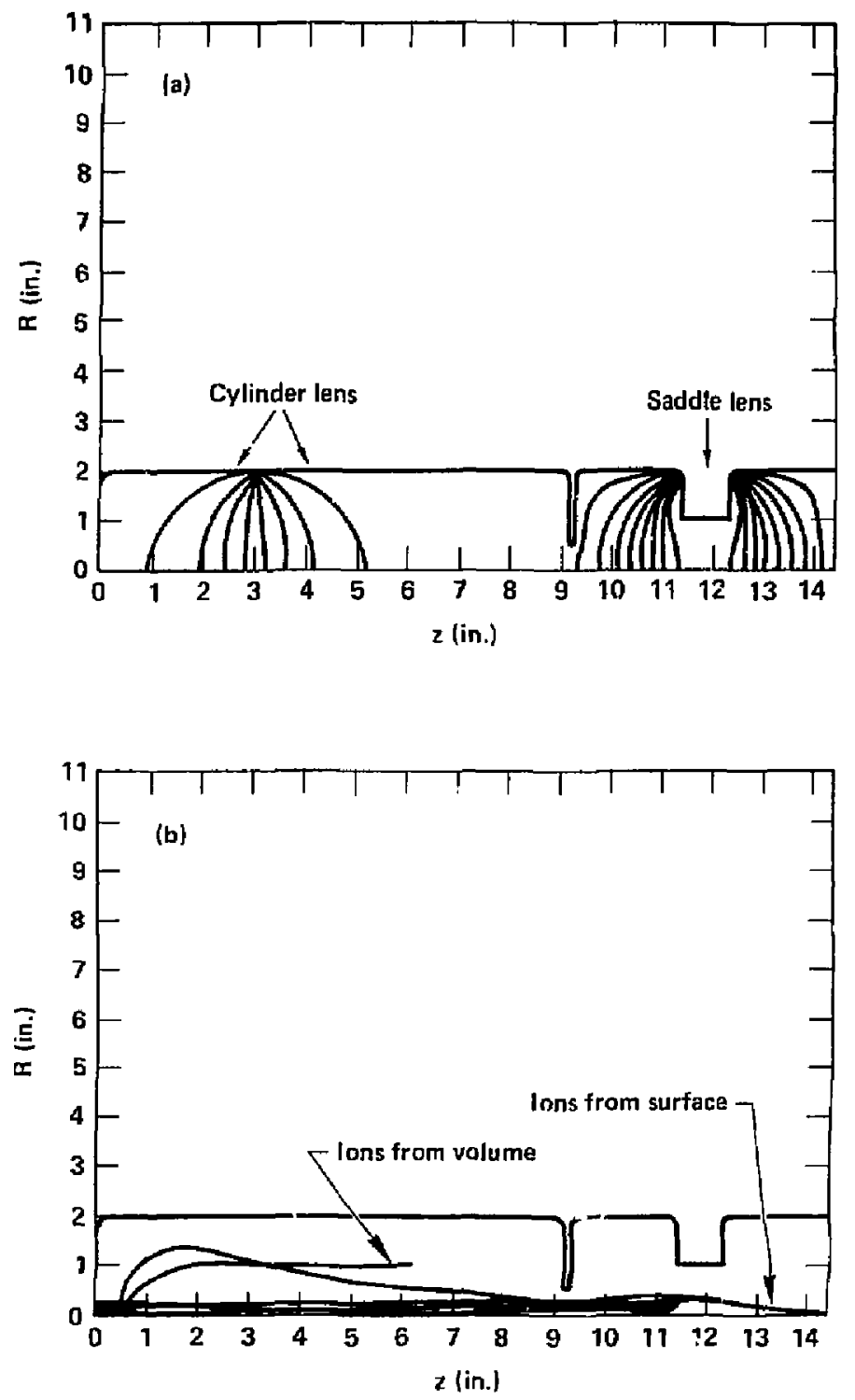

Fig. 5. (a) Potential energy contours calculated for this lens.

(b) Trajectories are plotted for hydrogen atoms that have been iontzed at the surface and within the volume. Note that protons that have originated to the right of the extraction grid are turned back at the saddle lens. 
where $\mathrm{G}$ is the detector gain $\left(1.2 \times 10^{7}\right), \varepsilon$ is the detector efficiency (0.5), and $T_{1}$ and $T_{2}$ are the transmission factors of the first and second grids, respectfully.

The largest source of error in Eq. (3) Ties in choosing the appropriate value for $\varepsilon$, the detector efficiency. This is because the efficiency is not measured dircatiy during the gain measurements. Instead, the ratio of active channel area to total detector area is used for the efficiency factor. At the IOw proton energies in this experiment, this assumption is not unreasonable. ${ }^{5}$ Another possible source of error lies in the assumption that no protons are lost by collisions with the detector walls. Trajectory calculations, however, indicate that this does not occur.

\section{EXPERIMENTAL PROCEDURE AND RESULTS}

Samples of beryllium, carbon, aluminum, tantalum, and gold in the fom of

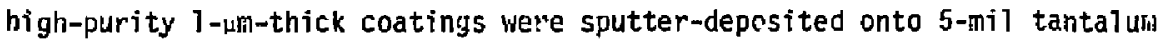
foils. These deposited tantalum foils were sandwiched between the hard tantalum aperture and the extraction grid as shown in Fig. 3, and inounted together with the detector on the vacuum side of the Febetron drift tube. The assembly was then evacuated to a nominal pressure of $3 \times 10^{-6}$ torr.

Tine-of-flight mass spectra were recorded by firing the Febetron and using the electromagnetic pulse from the electrons to trigger both the turn-on of the channel plates and the oscilloscope sweeps. An array of 7912AD digitizing oscilloscopes recorded the sweeps. The anode voltage response (mass scans) and a corresponding $x$-ray diode signal were digitized and put on compiter files for iater analysis. The total number of protons released from the sample during a shot was detemined using Eq. (3).

In order to obtain absolute photoelectron desorption cross sectians, it is necessary to calibrate the $x$-ray diode respcnse measured during mass scans to the tota? number of photoelectrons passing through the sample. This calitration is done by seating off the time-of-flight tube so that no electrons can escape, and then measuring the voltage induced during severa 1 shots. The total photoelectron charge is determined using the relation

$$
Q_{p e}=\mathrm{CV} \text {, }
$$

where $C$ is the measured capacitance of the assembly and $V$ is the voltage difference between the grounded sample and the time-of-flight tube. A typical 


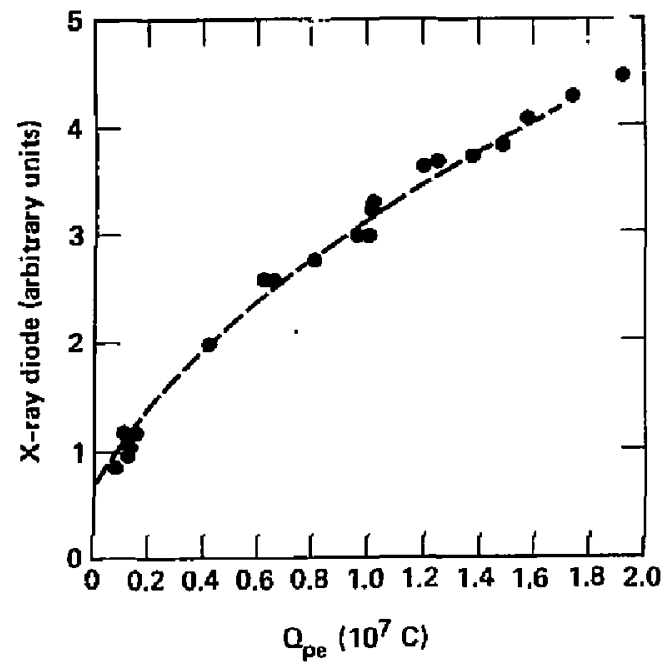

Fig. 6. Calibration curve of x-ray diode in terms of total photoelectron charge.

calibration curve is shown in Fig. 6, where we have plotted total photoelectron charge verses the $x$-ray diode response. The curvature at high fluxes is due to diode saturation.

The ratio of the total proton charge to photoelectron charge gives the probability of $\mathrm{H}^{+}$desorption per photoelectron. This desorption probatility depends on the hydrogen surface coverage. Absolute cross sections can on $1 y$ be obtained by estimating the surface concentration of hydrogen. For these experiments we used the value of $2 \times 10^{74} \mathrm{H} / \mathrm{cm}^{2}$, which is consistent $\mathrm{r}^{\text {ith }}$ a monolayer coverage.

Table 1 gives the values for the hydrogen desorption probabilities and absolute cross sections for the metal surfaces we studied. These are compared with values obtained by other workers studying low-energy-electron-stimulated desorption. These numbers are uncertain to the extent that surface coverage is uncertain. In fact, the increase in the desorption cross section from the low- $Z$ to the high $Z$-coatings that we observe may be due to differences in the surface coverage. Therefore, we are currently attempting to measure the hydrogen surface coyerage using thermal desorption techniques. These measurements will be described in a forthcoming paper. 
Table 1. Hydrogen desorption probabilities and absolute cross sections.

\begin{tabular}{lcccll}
\hline Substrate Ion & $\begin{array}{c}\text { Probability } \\
\left(\mathrm{H}^{+} / \mathrm{e}^{-}\right)\end{array}$ & $\begin{array}{c}\text { Absolute cross section, } \\
\sigma_{\mathrm{d}}\left(\mathrm{cm}^{2}\right)^{\mathrm{a}}\end{array}$ & Electron energy Reference \\
$\mathrm{Be}$ & $\mathrm{H}^{+}$ & $4 \times 10^{-10}$ & $2 \times 10^{-24}$ & $>200 \mathrm{keV}$ & This work \\
$\mathrm{C}$ & $\mathrm{H}^{+}$ & $8.38 \pm 1.38 \times 10^{-10}$ & $4 \times 10^{-24}$ & $>200 \mathrm{keV}$ & This work \\
$\mathrm{C}$ & $\mathrm{H}^{+}$ & - & $210^{-22}$ & $<150 \mathrm{eV}$ & Ref. $\mathrm{i}$ \\
$\mathrm{A}$ & $\mathrm{H}^{+}$ & $2.5 \times 10^{-10}$ & $5 \times 10^{-24}$ & $>200 \mathrm{keV}$ & This work \\
$\mathrm{Ta}$ & $\mathrm{H}^{+}$ & $3 \times 10^{-9}$ & $6 \times 10^{-23}$ & $>200 \mathrm{keV}$ & This work \\
$\mathrm{W}$ & $\mathrm{H}^{+}$ & - & $3 \times 10^{-27}$ & $<150 \mathrm{eV}$ & Ref. 7 \\
$\mathrm{Au}$ & $\mathrm{H}^{+}$ & $1.93 \pm 0.17 \times 10^{-9}$ & $1 \times 10^{-23}$ & $>200 \mathrm{keV}$ & This work
\end{tabular}

absolute cross sections based lipon an assumed hydrogen surface ccuerage of $2 \times 10^{14} / \mathrm{cm}^{2}$.

\section{DISCUSSION}

$X$ rays incident on, and passing through, a metal surface produce electrons by photoelec+ric capture, Culipton scattering, and pair produrtion (only possible at very high energy). These electrons, in turn, câĭ desor s ga's molecules by exciting the surface bonds. The number of indrogen atoms, $Q_{H}$, removed by electron-stimulated desorption per incident $f] u x$ of $x$ rays is

$$
Q_{H}=\theta \int_{0} f(\varepsilon)\left[\int_{\max }^{E_{\max }} \pi(\varepsilon)_{Y}(E) d E\right] d \varepsilon,
$$

where $\theta$ is the fraction of available desorption sites occupied by hydrogen atoms, $f(\varepsilon)$ is the hydrogen yield per electron of energy $\varepsilon$ for a fully occupied surface, $n(\varepsilon)$ is the number of photoelectrons of energy $\varepsilon$ produced by an $x$ ray of energy $E$, ind $\gamma(E)$ is the number of photons with energies beiween $E$ and $E+d E$. Once $f(\varepsilon)$ and $\eta(\varepsilon)$ are known, $Q_{H}$ can be calculated for any $x$-ray spectrum and surface coverage. 
The messurenents of $f(\varepsilon)$ and $n(\varepsilon)$ are two separate problems. In this experi, nt, the double integral of $n(\varepsilon) \gamma(E)$ was measured directly and the energy distribution of the photoelectrons was later calculated using the SANDYL code. ${ }^{3}$ The calcuiated photoelectron energy spectrun was used to give a spectrum-averaged desorption probability, P. Therefore, the total hydrogen yield can be calculated fron

$$
R_{H}=O P N_{\nu} Y,
$$

where $N_{r}$ is the $x$-ray fluence and $Y$ is the total quanum yield (electrons/incident photon). This linearity between proton yie ld and photon flux is demonstrated in Fig. 7. Because the photoelectron energy spectrum is sharply peaked above $200 \mathrm{keV}$, the spectruln-averaged value, $P$, can be raugily equated to $f(\varepsilon)\}_{\varepsilon=200 \mathrm{kev}}$. This is not entirely cor:ect, however, since we have not included the low-energy secondary electron flux that is present.

The desorption crass section $\left[\sigma_{\mathrm{i}}\left(\mathrm{cm}^{2}\right)\right]$ is related to the desorption probability, $f(\varepsilon)$. chrough the value of $u$. If we assume that $\theta$ is equal to 1 in this experiment, then we ubtain desorption cross sections of $10^{-23}$ to $10^{-24} \mathrm{~cm}^{2}$. The electron impact ionization cross section for hydrogen

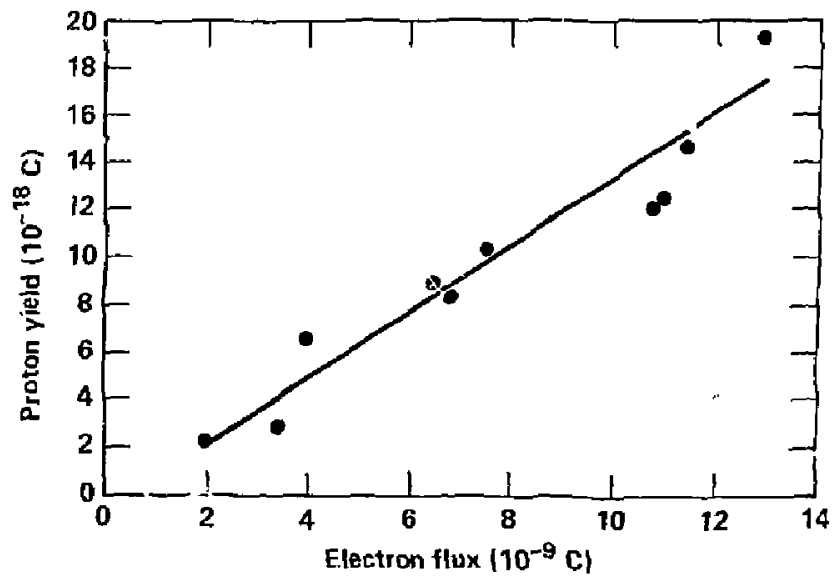

Fig. 7. Proton yield ys electron flux for desorption from a gold surface. 
atoms in the gas phase is $1.0 \times 10^{-19} \mathrm{~cm}^{2}$ for $500-k e V$ electrons. ${ }^{8}$ Since the excitation mechanism may be similar for surface ionization and gas-phase ionization, the greatly reduced desorption cross sections must be the result of reneutratization of the hydrogen ions at the surface.

The ionic desorption cross section is related to the gas-phase ionization cross section, $a_{0}$, by

$$
\sigma_{d}=\sigma_{0}^{R},
$$

where $R$ is the ion escape probability:

$$
R=e^{-t_{r} / T},
$$

where $t_{r}$ is the time that the ion spends in the electronic interaction vicinity of the surface, and $\tau$ is the lifetime of the ionic state at the surface.

The Iifetime of an excited atomic state at a free surface depends critically on both the distance of the adsorbed species from the surface and the electronic density of states of the metal. These, in turn, depend critically on surface structure as well as atomic number. Because of this, the desorption cross section is a furction of surface preparation, and the results that are published here for deposited metal surfaces may not be correct for polycrystailine materials or single crystais.

We can estimate the lifetime of $\mathrm{H}^{+}$ions at a surface fron the measured desorption cross sections using Eq. (8). First, we assume that the reneutralization matrix elements are position-independent over a distance of the order of $1 A$. Second, we assume that the average escape energy of the hydrogen ions is $5 \mathrm{eV} .^{9-12}$ Then the residence time, $t_{R}$, is

$$
t_{R}=\Delta X\left(2 E_{k} / m_{p}\right)^{-1 / 2}=3.2 \times 10^{-15} \mathrm{~s} \text {, }
$$

where $E_{k}$ is the escape energy $(\sim 5 \mathrm{eV}), m_{p}$ is the rest mass of the hydrogen $i$ on, and $\Delta X$ is the effective interaction distance ( $\sim A$ ). Using these yalüs, we find that the lifetime of the excited hydrogen atom at the surface is of the order of $10^{-16}$ seconds. This is what is expected from quantum mechanical calculations, which predict lifetimes from $10^{-17}$ to $10^{-16}$ seconds. $\$ 3$ 
Before these results can be used to predict ion desorption yields for an arbitrary $x$-ray spectrum, it is necessary to know the energy dependence of the cross sections as well as the nature of the surface hytrogen coverage. We have already alluded to a method for extracting the energy dependence using Eq. (7) with the appropriate value for the reduction factor. If collective effects are unimportant, the reduction factor is, to first order, independent of the $x$-ray energy: Therefore, the energy dependence of the cross section should depend only on the gas-phase electron excitation cross section (assuming that the presence of a surface has little effect on the electronic wave functions of weak7y bound adsorbates). In practice, however, Eq. (7) may be difficult to apply since it requires detailed information on the photoelectron energy spectrum as well as knowledge of the structure of the molecule giving rise to the desorption.

The photoeiectron spectrum generated by the Febetron was deternined up to 500 eV by reverse-biasing the extraction grid during the total charge measuruments. The SANDYL calculations were used to extend the spectruin beyond $500 \mathrm{eV}$. A surprising result was that fewer than 5\% of the photoelectrons had energies less than $200 \mathrm{eV}$; earlier experiments on photoelectron emission from gold indicated this percentage should be closer to $20 \% .{ }^{14}$

Two possibilities come to aind which might explain the low secondary yield observed in these measurements. The first possibility is based upon the observation that during the total clarge measurements the collector rapidiy (in 210 ns) reaches negative pots: , ais larger than $-20 \mathrm{~V}$. Since the najority of the secondary electrons have energies less than this, they may be turned back before being collected. This does not affect in results of the cross-section measurenents, however, because the desorption threshold is around $20 \mathrm{eV} .^{15}$ The second, and more interesting, possibility is that the presence of a thin coating reduces the escape of secondaries because of a change in the electronic density of states at the interface.

The appropriate gas-phase cross section to use in Eq. (7) depends upon what kind of electronic transition is responsible for desorption. Residual gas analysis of the vacuur: used in our experiment indicated that the predominant source of hydrogen is water vapor. If the water vapor is simply physisorbed on the surface, then the electronic transition responsible for desorption of hydrogen would involve the fractionation of $\mathrm{H}_{2} \mathrm{O}$ into a proton and an oll radical. Furthermore, a large $\mathrm{H}_{2} \mathrm{O}^{+}$signal should be abserved. 
On the other hand, if $\mathrm{H}_{2} \mathrm{O}$ dissociates on the surface, then protons aight originate from impact ionization and fragmentation of $\mathrm{OH}$ on the surface. The observation that the threshold energy for desorption is grater than $30 \mathrm{eV}$ makes it unlikely that desorption is due to impact ionization of atomic hydrogen. Instead, this high threshold energy indicates that a two-electron transition may be occurring. Furthemore, the 5-6-eV proton energles are much greater than the predictions of Thonas-Femi models for bare protons desorbing from a surface. 16

A more likely case can be made for the fragmentation of oH radicals. Fiist is the observation from the data that the predominant desorbed ion species are $\mathrm{H}^{+}, \mathrm{H}_{2}^{+}$, and $\mathrm{OH}^{+}$. Very few $\mathrm{H}_{2} \mathrm{O}^{+}$ions are observed. Second, physisorbed $\mathrm{H}_{2} \mathrm{O}$ molecules are not usually stable on clean surfaces above room temperature. If an oxide surface is present, as it definitely is with the beryllium, aluminum, and tantalum surfaces, the $\mathrm{H}_{2} \mathrm{O}$ molecule dissociates into a chemisorbed $\mathrm{OH}$ radical. 17-19 The reaction is

$$
\mathrm{H}_{2} \mathrm{O}\left(\mathrm{g} ;+\mathrm{O}_{(\mathrm{a})} \rightarrow 2 \mathrm{OH}_{(\mathrm{a})}\right. \text {. }
$$

The small presence of $\mathrm{H}_{2} \mathrm{O}$ that is observed in the time-of-flight spectra may be due to jonization of any $\mathrm{H}_{2} \mathrm{O}$ formed by the back-reaction to Eq. (10). $\mathrm{H}_{2}$ most $7 \mathrm{jkely}$ is fomed by ionization and fragmentation of hydrocarbons.

\section{CONCLUSION}

We have measured the desorption cross sections for hydrogen ions frofi berylitum, carbon, aluminum, tantalun, and gold surfaces. The results of the studies give values for the cross sections ranging between $2 \times 10^{-24} \mathrm{~cm}^{2}$ and $6 \times 10^{-23} \mathrm{~cm}^{2}$. The increase in the desorption cross section with increasing $z$ of the substrate may not be a property of the desorption kinetics; rather, it may be due to differences in the hydrogen surface coverage that we hava not accounted for. This will be the subject of another study.

The small cross sections, as well as the lack of $\mathrm{H}_{2} \mathrm{O}^{+}$ions in the desorption mass spectra, indicate that the hydrogen ions originate from the fragmentation of chemisorbed $\mathrm{OH}$ radicals. These $\mathrm{OH}$ radicals are formed at room temperature when $\mathrm{H}_{2} \mathrm{O}$ molecules impinge upon a surface that has an oxide covering. 


\section{REFERENCES}

J. S. Brumbach and M. Kaminsky, J. Huc1. Mat. 63, 188 (1976).

2. B. L. Pruett, private -omunication, Lawrence Livemnore National Laboratory.

3. C. Cerjan, private communication, Lawrence Livermore National Laboratory.

4. J. H. Kinney, uripublished.

5. J. L. Wiza, Muc.1. Inst. Meth. 162, 587 (1979).

6. M. I. Datsiev and Y. I. Belyakov, Sov. Phys. Tech. Phys. 14, 848 (1969).

7. M. Nishijima and F. M. Propst, Phys. Rev. BZ, 2368 (1970).

8. C. F. Barnett, J. A. Ray, E. Ricci, H. I. Wilker, E. W. KcDanie1, E. W. Thomas and H. B. Gilbody, in Atomic Data for Controlled Fusion Research, 0ak Ridge Nlational Laboratory, Oak Ridge, TN, ORNL-5207 Vol. 2 (1977).

9. T. E. Madey and J. T. Yates, Jr., J. Vac. Sci. Tech. 8, 525 (1971).

10. J. H. Leck and B. P. Stimpson, J. Vac. Sci. Tech. 9, 293 (1971).

11. P. A. Redhead, Nuovo Cimento Suppl. 5, 586 (1967).

12. E. Batuer and H. Poppa, Surf. Sci. 99, 34T (1980).

13. H. Tsukada and W. Erenig, Z. Phys, B 23, 369 (1976).

14. J. I. Gaines ani R. A. Hansen, J. Applieci Plyys, 47, 3923 (1976).

15. H. J. Drinkwine, "Bombarding Electron Energy Effects in Electron Stinulated Desorption Studies. Electron energies: 50-6000 eV, "Ph.D. thesis, University of Wisconsin, Milwaukee, WI (1977).

16. J. H. Kinney, unpublished.

17. A. Spitzer, A. Ritz, and H. Liith, Surf. Sci. 152/753, 543 (1985).

18. E. M. Stuve, S. W. Jorgensen, and R. J. Madix, Surf. Sci. 146, 179 (1984).

19. K. Bange, T. E. Madey, and J. K. Sass, Surf. Sci. 152/153, 550 (1985). 


\section{CONTENTS}

Abstract

1. Int roduction

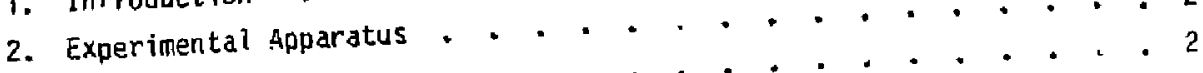

The X-Ray Source . . . . . . * . . . . . . 3

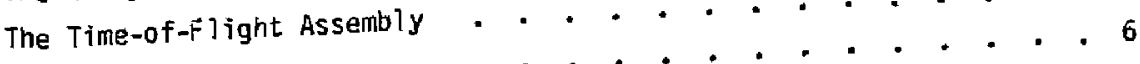

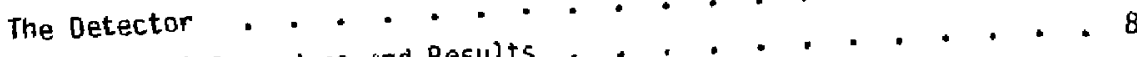

3. Experimental Procedure and Results . . . . . . . . . . . 10

4, Discussion . . . . . . . . . . . . . . 14

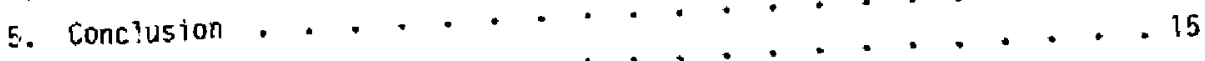

6. References

\section{DISCLAIMER}

This teport was prepared as an zocount of wark spansered by an agency of the United States Governmenl. Neither the United States Government nor any ageney thereol, nor any of their employees, makes any warrenty, express or implied, or assumes any legal limbility or respons:bility for the ascuracy, compleleness, or usef uness of any imfomation, apparalus, product, or process disetosed, or represents that its use would not infringe privalely owned rights. Refereлe herein to any specilie commerciol product, proces, of service by imde name, trademaric, manufacturer, or otherwise does not recessarily constitute or imply ils endorsement, tecom. mendation, or favoring by the Unized States Government or any agensy thereof. The views and opinions of authors expressed herein do not necessarily state or reflect those of the United States Govemment ar any agency thereof. 